\title{
Henneguya cynoscioni sp. n. (Myxosporea: Bivalvulida), an agent of severe cardiac lesions in the spotted seatrout, Cynoscion nebulosus (Teleostei: Sciaenidae)
}

\author{
Iva Dyková ${ }^{1}$, Isaure de Buron ${ }^{2}$, William A. Roumillat ${ }^{3}$ and Ivan Fiala ${ }^{1}$ \\ ${ }^{1}$ Institute of Parasitology, Biology Centre of the Academy of Sciences of the Czech Republic, Branišovská 31,37005 České \\ Budějovice, Czech Republic; \\ ${ }^{2}$ Department of Biology, College of Charleston, Grice Marine Laboratory, 205 Ft. Johnson Rd., Charleston, South Carolina 29412, \\ USA; \\ ${ }^{3}$ Marine Resources Division, Inshore Fisheries Section, South Carolina Department of Natural Resources, 217 Ft. Johnson Rd., \\ Charleston, South Carolina 29412, USA
}

\begin{abstract}
A new myxosporean species, Henneguya cynoscioni sp. n., is described from the spotted seatrout, Cynoscion nebulosus (Cuvier) (Sciaenidae) as a causative agent of cardiac henneguyosis. This new myxosporean species is characterized by the morphology of spores and the sequence of SSU rDNA. Examination of 227 spotted seatrout from four South Carolina estuaries in 2008-2010 revealed a $33.5 \%$ total prevalence of $H$. cynoscioni. Henneguy a cynoscioni produces lesions in the bulbus arteriosus, its specific site of infection. The severity of lesions and their impact on the bulbus arteriosus is proportional to the number of plasmodial stages developing in this segment of the heart, being most pronounced in host reaction directed against spores liberated from plasmodia.
\end{abstract}

Keywords: Henneguya cynoscioni, Myxosporea, pathogenicity, cardiac henneguyosis, Cynoscion nebulosus, Cardicola laruei, Atlantic Ocean

The spotted seatrout, Cynoscion nebulosus (Cuvier), is a sciaenid species found in the western Atlantic and the Gulf of Mexico (Robins 1991). It is a fish of high ecologic and economic importance (Vanderkooy and Muller 2003). In the state of South Carolina (SC), it became a game fish to preserve its prominent role in recreational activities and local economy. Population monitoring is regularly carried out by the SC Department of Natural Resources. The biology of this increasingly recognised fish species is quite well studied throughout its range of distribution (e.g., Bortone et al. 1997, Hendon et al. 2002, Bortone 2003, Roumillat and Brouwers 2004, Smith et al. 2008, Ward et al. 2008). In contrast, number of studies that include this fish species into screening for parasites is limited and these studies mostly focus on populations of C. nebulosus from the Gulf of Mexico (see review by Blaylock and Overstreet 2003). Studies on parasites involving populations of spotted seatrout from the western Atlantic were limited to that by Riekerk (1992) until very recently when Moravec et al. (2006), Perez et al. (2008), Dyková et al. (2009) and McVay et al. (2011) revealed previously unknown or unreported parasites from the US southeast, some of which with the potential to negatively affect the populations of this fish. The present myxosporean species that was found to infect the bulbus arteriosus of $C$. nebulosus is another newly discovered parasite with putative negative effect on the species populations in the western Atlantic. Description of this species and elucidation of its pathogenicity was the purpose of this study.

\section{MATERIALS AND METHODS}

In this study we follow Robins (1991) and use the officially accepted common name "spotted seatrout" for Cynoscion nebulosus (Cuvier) instead of "weakfish" mentioned in FishBase (Froese and Pauly 2010). This is in agreement with other authors (see review by Bortone 2003).

A total of 227 spotted seatrout were collected using seining, electrofishing and trammel netting in four estuaries of South Carolina from April 2008 through May 2010. Estuaries were from north to south, Winyah Bay, Bull's Bay, Charleston Harbor, and the Ashepoo-Combahee-Edisto (ACE) Basin. Fish were measured, weighed, and dissected within $6 \mathrm{~h}$ post capture. Tissues were processed accordingly to their further utilisation: histology, transmission electron microscopy, or molecular study.

For histology, hearts were fixed whole in Davidson's fixative for $48 \mathrm{~h}$, stored in $70 \%$ ethanol, and embedded in Histoplast $\mathrm{S}$ (Serva). Histological sections were routinely stained with hae-

Address for correspondence: I. Dyková, Institute of Parasitology, Biology Centre of the Academy of Sciences of the Czech Republic, Branišovská 31, 37005 České Budějovice, Czech Republic. Phone: +420 38777 5423; Fax: +420 38 5310388; E-mail: iva@paru.cas.cz 
matoxylin and eosin (HE) and Giemsa staining. In addition, Masson's trichrome and Verhoeff's staining procedures were applied in selected cases.

The results of histological examination turned our attention to lesions observed in the bulbus arteriosus. The myxosporean origin of these lesions was evidenced by Giemsa staining, which allowed us to suspect the presence of Henneguya spores. Spores were then collected from cases manifested by grossly visible lesions. Morphology of fresh spores was characterized following guidelines recommended by Lom and Arthur (1988). Measurements are the mean with the range in parentheses.

For transmission electron microscopy, tissue samples were fixed in cacodylate buffered $2.5 \%$ glutaraldehyde at $4{ }^{\circ} \mathrm{C}$, stored in cacodylate buffer with sucrose, rinsed in $0.1 \mathrm{M}$ cacodylate buffer and postfixed in $1 \%$ osmium tetroxide. After graded acetone dehydration, the samples were embedded in Spurr resin. Ultrathin sections were stained with uranyl acetate and lead citrate and examined in a JEOL JEM 1010 electron microscope operating at $80 \mathrm{kV}$. Images were collected with Megaview II soft imaging system using analySIS software.

For molecular studies, small pieces of fresh tissue of bulbus arteriosus containing plasmodial stages were fixed in 95\% ethanol. Prior to DNA extraction, samples were homogenized and myxospores were crushed using $0.5 \mathrm{~mm}$ glass beads in a FastPrep ${ }^{\circledR}-24$ Instrument (M.P. Biomedicals, CA, USA). Total DNA was extracted using the Genomic DNA Mini Kit (Geneaid Biotech, Taiwan). SSU rDNA was amplified by PCR with eukaryotic universal primers ERIB1 and ERIB10 (Barta et al. 1997). PCR was carried out in a $25 \mu 1$ volume using $2.5 \mu 1$ of $10 \times$ PCR buffer, $250 \mu \mathrm{M}$ of each dNTP, 20 pmol of each primer, $1 \mathrm{U}$ of Taq-Purple polymerase (Top-Bio, Czech Republic) and approximately $20 \mathrm{ng}$ of DNA. The PCR cycling conditions were as follows: $1 \mathrm{~min}$ at $95^{\circ} \mathrm{C}$, then 30 cycles of $30 \mathrm{~s}$ at $95^{\circ} \mathrm{C}$, $1 \mathrm{~min}$ at $50^{\circ} \mathrm{C}, 2 \mathrm{~min}$ at $72^{\circ} \mathrm{C}$, followed by terminal elongation of $10 \mathrm{~min}$ at $72^{\circ} \mathrm{C}$. PCR product of approximate size $2100 \mathrm{bp}$ was isolated from the agarose gel using the Gel/PCR DNA Fragments Extraction Kit (Geneaid Biotech, Taiwan) and cloned into pDrive Cloning Vector using QIAGEN PCR Cloning Kit (Qiagen, Germany). Both strands of PCR clone were sequenced on an ABI PRISM 3130x1 automatic sequencer (Applied Biosystems, Czech Republic).

The SSU rDNA sequence of Henneguya species studied was blasted against the sequences deposited in GenBank in order to verify the highest similarity with Henneguya/Myxobolus species. The alignment contained Myxobolus and Henneguya species closely related to Henneguya under study determined by BLAST search. Sequences of Myxidium lieberkuehni Bütschli, 1882 and Myxidium truttae Léger, 1930 were selected as outgroups. The alignment was constructed using MAFFT v6.626b (Katoh et al. 2005) with default parameters. Ambiguous characters were removed i) by eye in program SEAVIEW 3.2 (Galtier et al. 1996) and ii) using program Gblocks v091b (Castresana 2000) with default parameters. These two alignments were subjected to the phylogenetic analysis. Maximum likelihood (ML) analysis was carried out by program RAxML (Stamatakis 2006) with GTRGAMMA model and 500 bootstrap replicates. Maximum parsimony (MP) was performed in program PAUP*
$4.0 \mathrm{~b} 10$ (Swofford 2001) with heuristic search, random addition of taxa and Ts:Tv $=1: 2$. Bootstrap support was calculated from 1000 replicates. Distance estimation was carried out using the Kimura 2-parameter model.

\section{RESULTS}

Gross and/or histological examination revealed cystlike formations in the bulbus arteriosus of 33.5\% (76 out of 227) spotted seatrout examined. The lesions invariably had myxosporean origin and represented either developing plasmodia or, more frequently, advanced stages of host reaction. They were found in fish ranging from $276 \mathrm{~mm}$ to $663 \mathrm{~mm}$ in total length.

\section{Henneguya cynoscioni sp. n.}

Figs. 1-8

Morphological description. Light microscopy: Spores collected from fresh material displayed features typical of the genus Henneguya Thélohan, 1892 (Fig. 1). They were characterized as follows: oval/ovoid in frontal view; anterior end blunt, posterior end attenuated; shell valves thick; sutural view elliptical (biconvex spore body compressed parallel to sutural plane); sutural ridge distinctive; two tapering caudal appendages of equal length; two pyriform polar capsules (PC) equal in size, symmetrical and convergent; number of polar filament coils 3-4.

Measurements (based on 20 fresh spores): total length 38.60 (34.30-44.10) $\mu \mathrm{m}$; body length 10.40 (9.80-11.70) $\mu \mathrm{m}$; body width $8.82 \mu \mathrm{m}$; body thickness $5.88 \mu \mathrm{m}$; maximum length of PC $3.30 \mu \mathrm{m}$; maximum width of PC $2.00 \mu \mathrm{m}$; length of caudal appendages 28.05 (23.50 33.30) $\mu \mathrm{m}$.

Transmission electron microscopy: Sporogenesis takes place in disporic trophozoites (Figs. 2, 7); spores contain a binucleate sporoplasm (Fig. 2); the cytoplasm of adjacent enveloping cells contains numerous microfibrils with parallel orientation that are precursors of microfibrils in spore appendages (Figs. 2, 6); robust shell valves join in distinctive suture; polar filament (hardly discernible with light microscope) forms 3-4 coils (Figs. 3, 4); glycocalyx-like sheet envelopes the whole spore (Figs. 5, 8).

Histology: Plasmodia large, polysporic with striated zone of pinocytotic channels on the periphery (Fig. 11); typically present within the wall of bulbus arteriosus, mostly in the layer of highest density of elastic fibres; exceptionally found in atrioventricular and ventricobulbar valves (Figs. 12, 13).

Molecular characterisation. The SSU rDNA sequence is deposited in the GenBank database under Acc. No. JN017203. The BLAST result supported the position of $H$. cynoscioni within the Henneguya/Myxobolus clade and came with the highest match to $H$. pagri infecting the heart of red sea bream, Pagrus major (Temminck et 


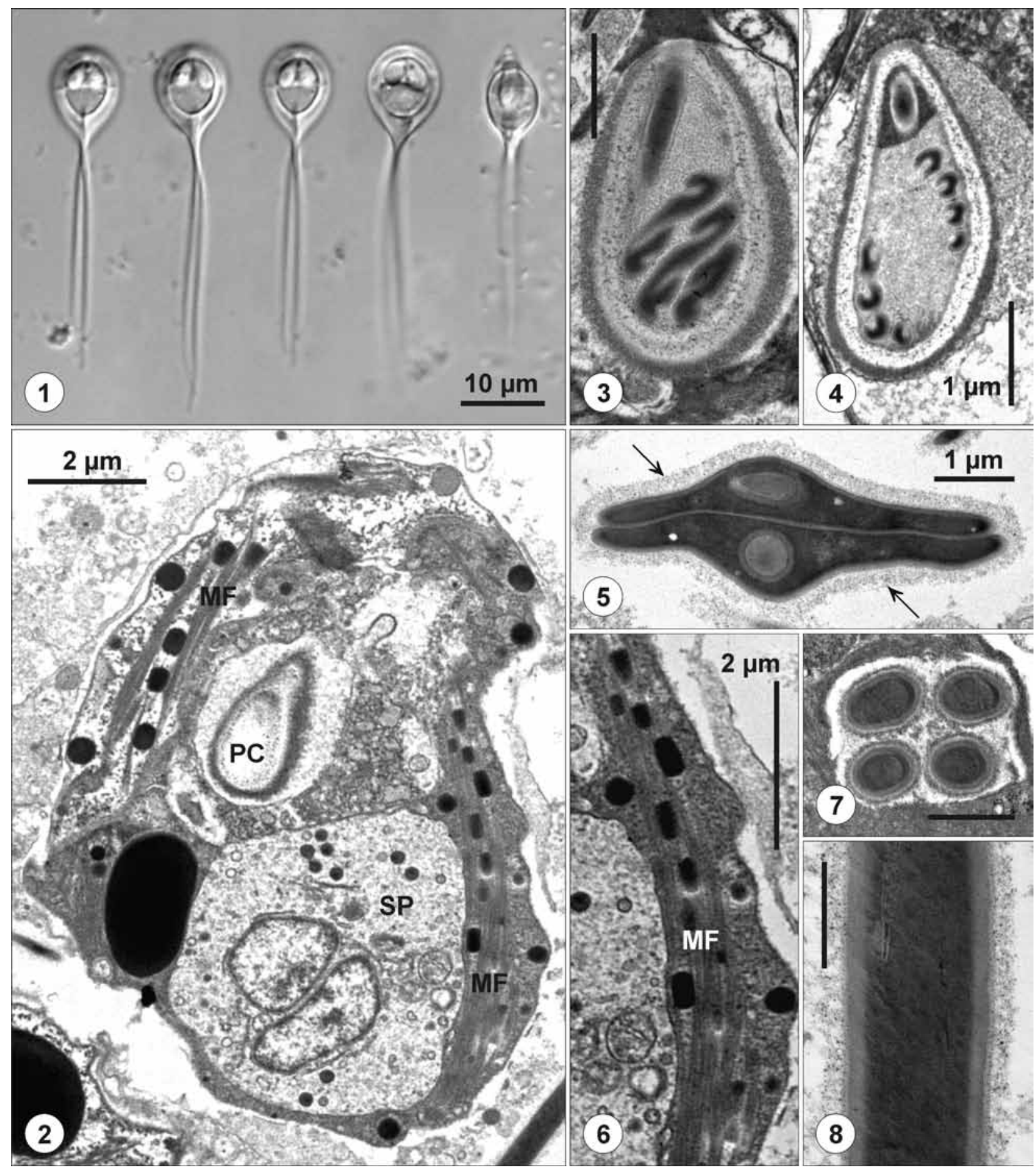

Figs. 1-8. Spores of Henneguya cynoscioni sp.n.; light microscopy and details of ultrastructure. Fig. 1. Mature spores as seen in Nomarski differential interference contrast. Four spores in full frontal view, one (on the right) in side view. Fig. 2. Sporogonic stage in thin section with developing polar capsule (PC), binucleate sporoplasm (SP), and bundles of microfibrils (MF) with parallel orientation and extremely dense inclusions. Figs. 3, 4. Polar capsules of mature spores shown in different levels of sectioning demonstrate number of coils of polar filament. Both figures same scale. Fig. 5. Cross-section through spore body transition to caudal appendages. Glycocalyx-like sheet (arrows) envelopes the spore including caudal appendages. Fig. 6. Detail of microfibrilar structure seen also in Fig. 2. Fig. 7. Cross-section through closely apposed caudal appendages of two spores developing in disporic trophozoite. Fig. 8. Longitudinal section through caudal appendage covered with glycocalyx-like material. Scale bars: Fig. $7=1 \mu \mathrm{m}$; Fig. $8=500 \mathrm{~nm}$. 


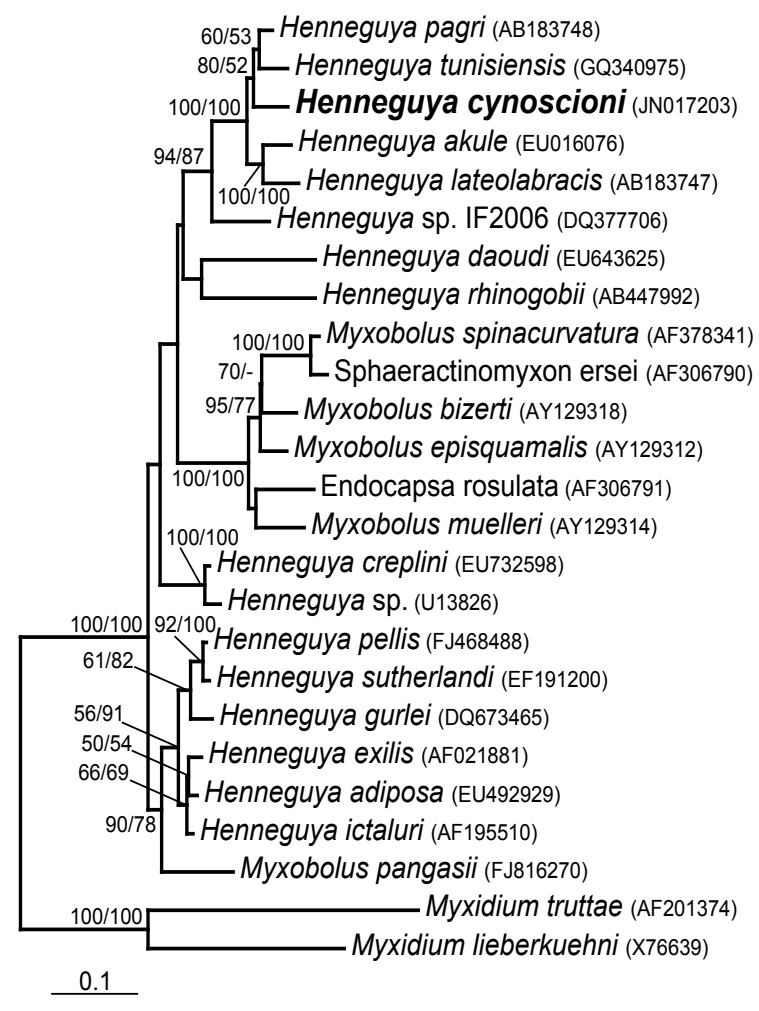

Fig. 9. Phylogenetic position of Henneguya cynoscioni sp. n. within the clade of closely related Henneguya and Myxobolus species. Maximum likelihood tree (likelihood $=-8358.2049$ ) with GTRGAMMA model of evolution. Numbers at the nodes represent bootstrap values (ML/MP) for the nodes gaining more than $50 \%$ support. Scale bar is given under the tree.

Table 1. The SSU rDNA sequence similarities of selected Henneguya spp. and Myxidium lieberkuehni.

\begin{tabular}{|c|c|c|c|c|c|c|}
\hline & 1 & 2 & 3 & 4 & 5 & 6 \\
\hline \multicolumn{7}{|l|}{1 Henneguya cynoscioni } \\
\hline 2 Henneguya pagri & \multicolumn{6}{|l|}{0.9043} \\
\hline \multicolumn{7}{|c|}{3 Henneguya lateolabracis 0.86920 .8812} \\
\hline 4 Henneguya akule & \multicolumn{6}{|c|}{$\begin{array}{llll}0.8673 & 0.8790 & 0.8890\end{array}$} \\
\hline 5 Henneguya tunisiensis & \multicolumn{6}{|c|}{$\begin{array}{llll}0.8913 & 0.9172 & 0.8718 & 0.8758\end{array}$} \\
\hline 6 Henneguya ictaluri & \multicolumn{6}{|c|}{$\begin{array}{lllll}0.8304 & 0.8255 & 0.8122 & 0.8247 & 0.8280\end{array}$} \\
\hline 7 Myxidium lieberkuehni & 0.7377 & 0.7280 & 0.7280 & 0.7312 & & 50.7470 \\
\hline
\end{tabular}

Schlegel). The close relation of $H$. cynoscioni to $H$. pagri was proved by comparison of SSU rDNA sequence similarities of selected sequences under study (Table 1). Phylogenetic analyses that were applied supported the position of $H$. cynoscioni within the group of Henneguya pagri Yokoyama, Itoh et Tanaka, 2005, H. tunisiensis Bahri, Marton, Marques et Eszterbauer, 2010, H. akule Work, Takata, Whips et Kent, 2008 and H. lateolabracis Yokoyama, Kawakami, Yasuda et Tanaka, 2003 with high bootstrap values. ML and MP analyses of alignment with "by eye" selected unambiguous sites (1760 of the original 2276 positions) supported close relationships of $H$. cynoscioni and $H$. pagri (Fig. 9). In this tree, the most closely related taxon to $H$. pagri was $H$. tunisiensis, whereas $H$. cynoscioni was their sister species. ML analysis of the alignment based on the Gblocks selection of position (1316 of the original 2276 positions) showed the closest relation of $H$. cynoscioni to $H$. pagri (data not shown). MP analysis of this alignment was the same as shown in Fig. 9.

Remarks. In order to summarize the data available for determination of $H$. cynoscioni, the widely accepted combination of morphological and molecular characteristics of spores was used. Based upon the phylogenetic analysis of data that are currently available, the number of Henneguya species for which it is logical to compare morphological data with $H$. cynoscioni is reduced to four (Fig. 9): H. lateolabracis, H. pagri, H. akule, and H. tunisiensis. Henneguya cynoscioni differs from $H$. lateolabracis in having slightly wider spores with much shorter caudal appendages; from $H$. pagri and $H$. tunisiensis in the absence of long "whip-like" flexible extensions of caudal appendages; from $H$. tunisiensis also in having much smaller, more elliptical spores, and smaller polar capsules with smaller number of coil turns (3-4 vs. 4-5 in $H$. tunisiensis). Also, the SSU rDNA sequence of $H$. $c y$ noscioni could not be matched with any of those four Henneguya species sequences that grouped within the same cluster. Therefore, based upon differences in sequences of SSU rDNA (Table 1) and spore morphometry (Table 2), the Henneguya described in this study is considered to be a new species.

Table 2. Spore measurements (the mean; in $\mu \mathrm{m}$ ) of phylogenetically related species of Henneguya.

\begin{tabular}{|c|c|c|c|c|c|c|c|c|}
\hline \multirow[t]{2}{*}{ Species / host } & \multicolumn{3}{|l|}{ Body } & \multicolumn{2}{|c|}{ Polar capsules } & \multirow{2}{*}{$-\frac{\text { Caudal appendages }}{\text { length }}$} & \multirow[t]{2}{*}{ Site of infection } & \multirow[t]{2}{*}{ Authority } \\
\hline & length & width & thickness & length & width & & & \\
\hline H. cynoscioni sp. n. / Cynoscion nebulosus & 10.40 & 8.82 & 5.88 & 3.26 & 1.96 & 28.05 & bulbus arteriosus & Present study \\
\hline H. akule / Selar crumenophthalmus & 12.1 & 7.4 & 5.3 & 3.4 & 1.4 & 28.7 & bulbus arteriosus & Work et al. 2008 \\
\hline H. lateolabracis / Lateolabrax sp. & 10.7 & 7.5 & 6.2 & 3.4 & 1.7 & 37.7 & bulbus arteriosus & Yokoyama et al. 2003 \\
\hline H. pagri / Pagrus major & 10.50 & 7.50 & 5.90 & 3.1 & 1.6 & $29.6+20-35^{*}$ & bulbus arteriosus & Yokoyama et al. 2005 \\
\hline H. tunisiensis / Symphodus tinca & 13.1 & 9.1 & 8 & 4 & 2 & $28.7+10-15^{*}$ & gills & Bahri et al. 2010 \\
\hline
\end{tabular}

*flexible extensions of caudal appendages 

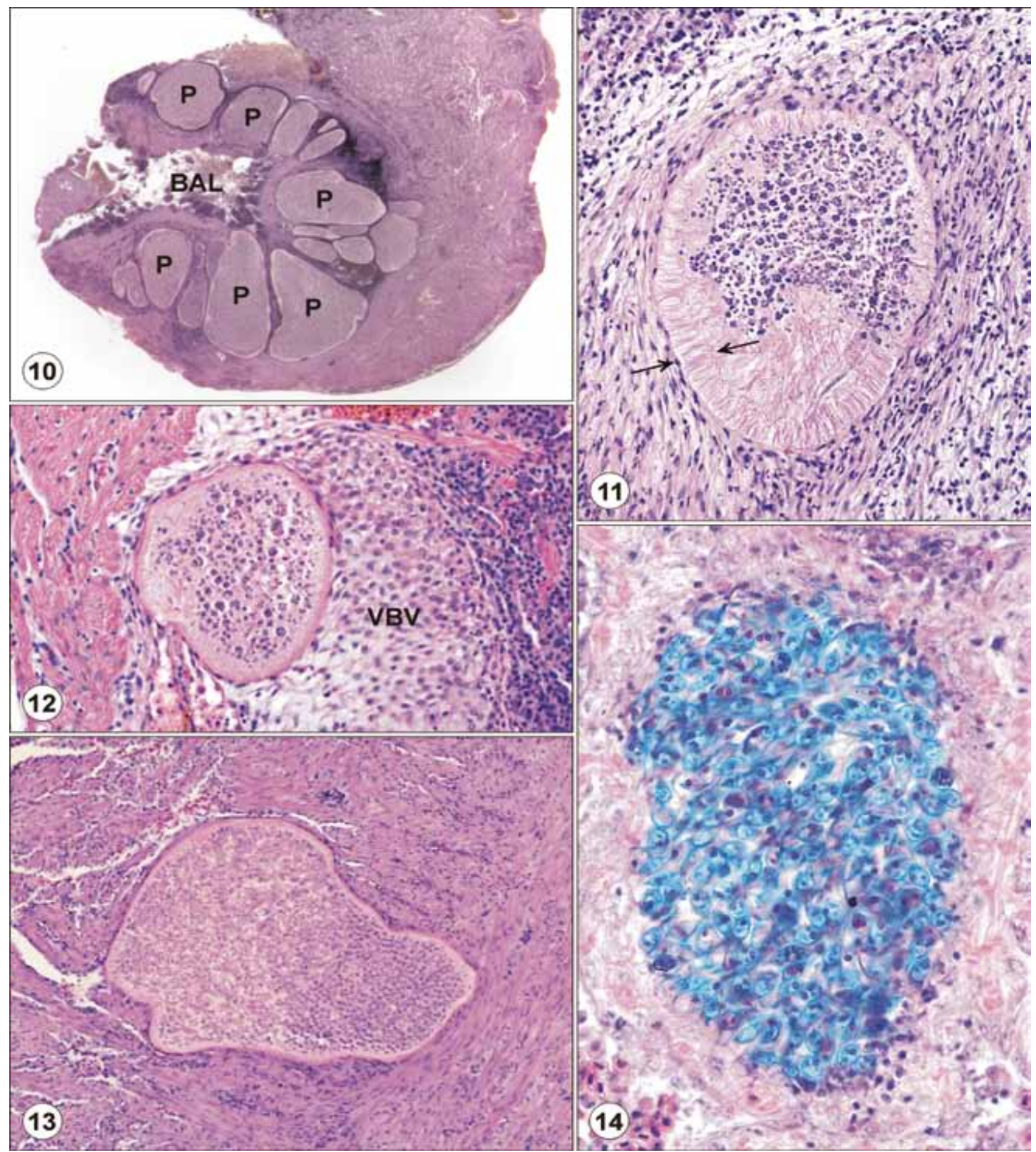

Figs. 10-14. Plasmodial stages and mature spores of Henneguya cynoscioni $\mathrm{sp}$. $\mathrm{n}$. in the heart of Cynoscion nebulosus; histological sections. Fig. 10. Overview of massive infection with $H$. cynoscioni as seen in almost transverse section through bulbus arteriosus with reduced diameter of lumen (BAL). Numerous plasmodial stages (P) are located in the wall of bulbus arteriosus. Verhoeff's staining for elastic fibres. HE, $\times 10$. Fig. 11. Early stage of development of plasmodium located in bulbus arteriosus. Arrows indicate striated zone on its periphery that corresponds to deep pinocytotic channels. HE, $\times 360$. Figs. 12, 13. Less frequent localisations of plasmodial stages in ventricobulbar valve (VBV) (Fig. 12) and atrioventricular valve (Fig. 13), producing partial atrophy of these structures. HE, $\times 340$ and $\times 170$, respectively. Fig. 14. Dense accumulation of mature spores liberated from plasmodium/a, with the first signs of host reaction. Giemsa, $\times 630$. 


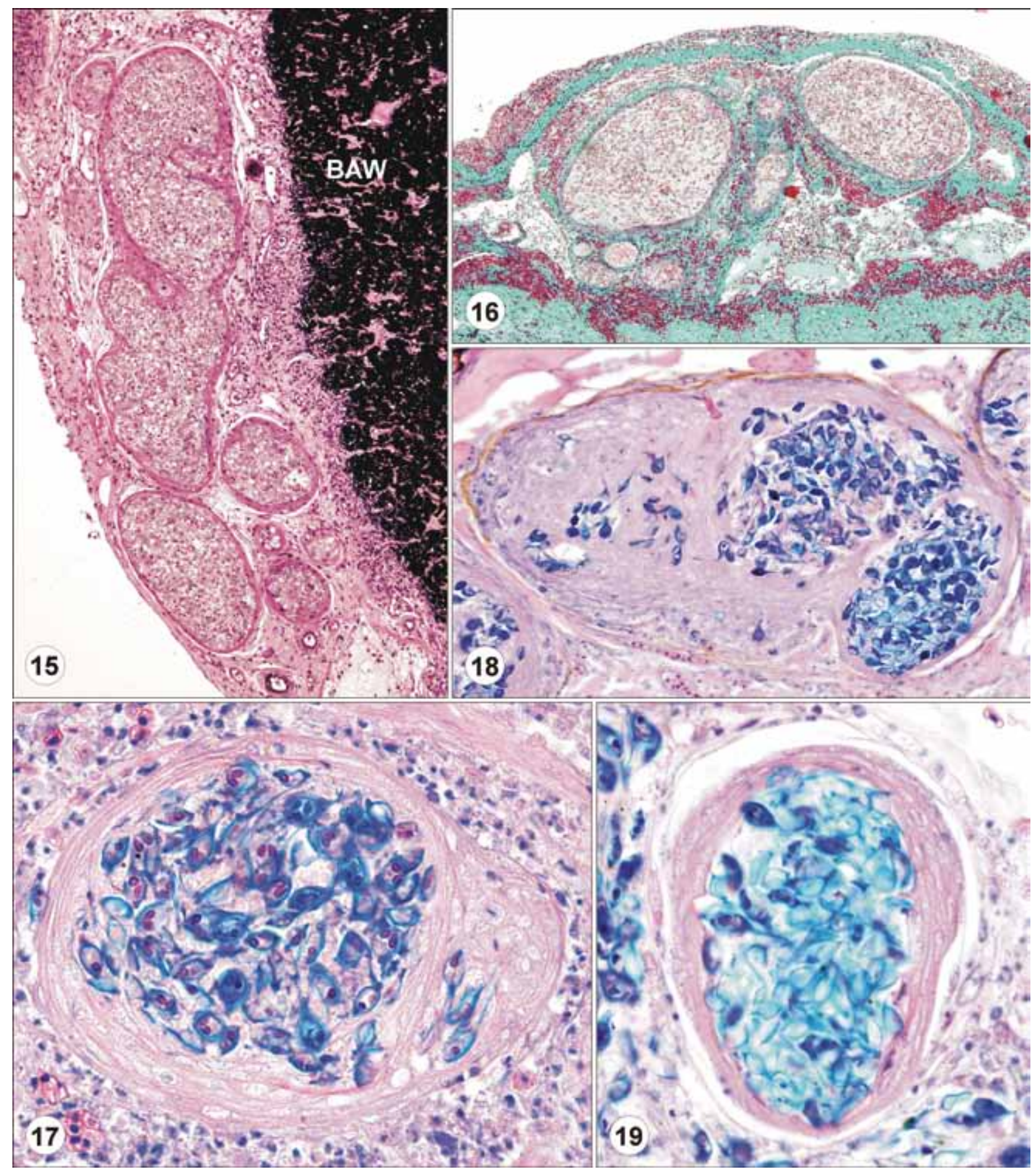

Figs. 15-19. Host reaction of Cynoscion nebulosus against mature spores of Henneguya cynoscioni sp. n. liberated from plasmodia. Fig. 15. Overview of granulomatous lesions produced in proliferating loose connective tissue covering bulbus arteriosus. Advanced granulomas with dense fibrous connective tissue on their periphery. Inner part of bulbus arteriosus wall (BAW) contains darkly stained elastic fibres. Verhoeff's staining, $\times 140$. Fig. 16. Advanced granulomas within oedematous subpericardial connective tissue accompanied by haemorrhages. Masson's trichrome, $\times 90$. Figs. 17-19. Series of granulomas that demonstrates progress in proliferative inflammation resulting in elimination of spores. In the final stage (Fig. 19), only remnants of spores, i.e., empty shell valves are seen together with involution of granuloma. Giemsa, $\times 710, \times 290$ and $\times 680$, respectively. 
Type host: Cynoscion nebulosus (Cuvier, 1830) (Perciformes: Sciaenidae).

Type locality: Low Ashley River, Charleston Harbor estuary, South Carolina, USA.

Other localities: Winyah Bay Estuary, Bull's Bay Estuary, Ashepoo-Combahee-Edisto Basin, South Carolina, USA.

Site of infection: Heart, the bulbus arteriosus. Spores were occasionally found also in gills.

Prevale n c e: $33.5 \%$ (76 fish positive/227 examined).

Type material: Phototypes and histological sections deposited in the collection of Institute of Parasitology, Biology Centre of the Academy of Sciences of the Czech Republic, Ceské Budějovice; SSU rDNA sequence deposited in GenBank under Acc. No. JN017203.

Etymology: Specific name refers to the generic name of the host.

\section{Pathogenicity of Henneguya cynoscioni}

Polysporic plasmodial stages developing within the bulbus arteriosus caused a hypertrophy of the wall of this heart segment. Due to the growth of plasmodia, the thickening of the wall was accompanied by a pressure atrophy changing the arrangement of connective tissue bundles. Most plasmodial stages started to develop at the limit between outer circular and inner longitudinally running bundles of elastic connective fibres. Due to the enormous size gradually reached by plasmodia, the structure of the bulbus arteriosus wall was noticeably altered. Simultaneous development of multiple plasmodial stages was followed by the loss of elastic connective tissue and undoubtedly also the loss of elastic properties of the bulbus wall (Fig. 10). The atrophy of tissue surrounding plasmodia was also observed in less frequent findings of plasmodial stages located within the atrioventricular and ventricobulbar valves (Figs. 12, 13).

Contrary to these tissue alterations of hypobiotic nature that were caused by plasmodial stages in the course of their growth and development (Figs. 10-13), intense host inflammatory reaction was induced by spores released from mature plasmodia. Spores liberated from plasmodia were observed in small or large aggregates within the walls of the bulbus arteriosus, the thin-walled atrium and, less frequently, cortical and trabecular layers of ventricle and the connective tissue of the epicardium (Fig. 14). Individual spores were found also in places distant from the heart, e.g., gills and interstitial tissue of the kidney. Foci of aggregated spores were often surrounded by haemorrhages. In the loose connective tissue underlying the visceral epicardium, mature spores were either accompanied by melanomacrophages and scattered infiltrating cells or surrounded by granulomatous inflammatory reaction (Figs. 15-19). Granuloma formations in early stages of their development were of histiocytic type and contained spores with well-stained details (shell valves, sporoplasm, and polar capsules). Advanced granulomas with dense layer of connective tissue on their periphery contained mostly degraded, "empty spores", i.e., spores with well-stained shell valves and appendages but no content inside (Fig. 19).

In addition to lesions in the bulbus arteriosus, small granulomas were found in the myocardium of $49.1 \%$ of all spotted seatrout examined and in $68.4 \%$ (52 of 76) of $H$. cynoscioni-positive seatrout. This granulomatous inflammatory reaction was found to be provoked by spindle-shaped eggs (smaller ones containing granular material and larger ones enclosing miracidia) of aporocotylid digeneans that probably were specimens of Cardicola laruei Short, 1953 as reported in C. nebulosus from the Atlantic shore of Florida in a recent study of McVay et al. (2011).

\section{DISCUSSION}

Henneguya cynoscioni is one of a few heart-infecting parasites that could be compared with other myxosporean species on the basis of both their morphology and the SSU rDNA sequences. Morphometric examination of spores revealed features common to numerous other Henneguya species; no species-specific feature was found using light microscopy. However, ultrastructurally, the glycocalyx-like sheet enveloping the whole spore should be mentioned as an uncommon feature. Same feature was described, although much more pronounced, by Azevedo and Matos (1995) in Henneguya adherens from gill filaments of Acestrorhynchus falcatus (Bloch), a characiform fish from Amazonia. No known function is attributed to this sheet. Regarding molecular data, since Yokoyama et al. (2005) reviewed heart-dwelling myxosporeans, new information from various studies on Henneguya species and new sequences of the SSU rDNA have extended the dataset available for phylogenetic analysis. Of particular interest to our study, Work et al. (2008) studied H. akule from the bulbus arteriosus of the bigeye scad, Selar crumenophthalmus (Bloch) and Bahri et al. (2010) studied H. tunisiensis from the gills of the east Atlantic peacock wrasse Symphodus tinca (L.). No information was given by the latter authors regarding examination of the heart of S. tinca; all other Henneguya species that clustered with $H$. tunisiensis (H. lateolabracis, H. pagri, H. cynoscioni) are heart-infecting species. It is to be noted (see below for details) that spores of all these three species were found also in the gills of their fish hosts. We suspect that this might be also the case of $H$. tunisiensis.

As noted above, spores of $H$. cynoscioni differ from those of $H$. lateolabracis in being slightly wider with much shorter caudal appendages, from those of $H$. pagri and $H$. acule by not showing long "whip-like" flexible extensions of caudal appendages, and from those of H. tunisiensis by being much smaller, more elliptical with smaller polar capsules and smaller number of coil turns.

Descriptions of other Henneguya and Myxobolus species previously diagnosed as agents of cardiac lesions 
were based solely on the morphology of spores. Thus, molecular data are missing for Henneguya otolithi Ganapathi, 1941 from the tigertooth croaker, Otolithes ruber (Bloch et Schneider) (syn. Otolithus ruber) and the blotched tiger-toothed croaker Pterotolithus maculatus (Cuvier) (syn. Otolithus maculatus); Henneguya sebasta Moser et Love, 1975 from the Bocaccio rockfish Sebastes paucispinis Ayres; Henneguya yoffensis Kpatcha, Faye, Diebakate, Fall et Toguebaye, 1997 from the blue spotted seabream Sparus caeruleostictus (Valenciennes); Henneguya sp. from the bluefish Pomatomus saltatrix (L.) (see Meyers et al. 1977) and Myxobolus etropli Rajendran, Vijayan et Alavandi, 1998 from the pearlspot Etroplus suratensis (Bloch). Of the species that show strict site specificity, selecting the bulbus arteriosus as the only site of infection, $M$. etropli is of special interest because it is common to brackish-water fish as is H. cynoscioni whereas most Henneguya species mentioned above infect marine fishes. Although spores of M. etropli differ substantially from Henneguya spores, they possess wing-like outgrowths at the posterior end that give the impression of predecessors of the caudal appendages in Henneguya. Other Myxobolus species whose spores were recorded from fish hearts (e.g., M. cordis Keysselitz, 1908; M. bulbocordis Massoumian, Baska et Molnár, 1996; M. paralintoni Li et Desser, 1985; M. colossomatis Molnár et Békési, 1993) were not sequenced and information on the exact site of development of plasmodia within heart is not available for all. The data presented herein resulted from the observation of numerous infected fish. They supplement data collected on agents of cardiac henneguyosis to date and bring new insight into the pathogenicity of Henneguya species affecting organs of vital importance for the fish. In teleosts, the main component of the cardiac outflow is the bulbus arteriosus, an elastic chamber organized into layers containing myofibroblasts, smooth muscle cells, collagen and elastin fibres organized in species-specific patterns (Icardo et al. 2000). The bulbus arteriosus is, therefore, very important in regulating the pressure of the blood leaving the fish heart. The elastic fibres allow this chamber to expand during the high pressure of the ventricular systole, protecting the delicate vessels of the gill lamellae from excessive distension. The alterations of the bulbus arteriosus architecture, including a loss of elasticity, undoubtedly affect this most important function of this cardiac segment. In cases of severe alterations caused by $H$. cynoscioni the function of the bulbus arteriosus cannot be fully compensated and progressive healing, such as mentioned by Meyers et al. (1977) for Henneguya sp. infection of the bluefish Pomatomus saltatrix, cannot restore elasticity of the bulbus arteriosus since lesions are repaired only with collagenous tissue. A loss of elastic fibres in heavy M. etropli infections of the brackish-water cichlid Etroplus suratensis was also reported by Rajendran et al. (1998). However, the comparison of pathological processes is difficult due to confusion in the terminology employed by the latter authors for plasmodia and "cysts".

The site specificity for the bulbus arteriosus has been reported for several Henneguya species. Of these, pathogenicity of $H$. sebasta described by Moser and Love (1975) from the bulbus and truncus arteriosus of seven rockfish species, Sebastes spp., awaits re-evaluation. Based on gross lesions and findings of spores in the heart chambers, these authors mentioned the possibility of pathogenic influence but did not evidence harmful effect of $H$. sebasta on its hosts. For two species of Henneguya of special interest to this study, H. pagri infecting the red seabream, Pagrus major (see Yokoyama et al. 2005) and $H$. lateolabracis infecting the seabass Lateolabrax sp. (see Yokoyama et al. 2003), pathological changes were also described in gills following maturation of plasmodial stages in the bulbus arteriosus. The influx of spores into the gills was shown to cause congestion of the gill capillaries and resulted in proliferative branchitis. Both cases exemplified that heavy infections not only do impair heart function but also cause destruction of gill capillaries by spores liberated from former plasmodial stages, i.e., condition that is followed by mortalities. In the case of C. nebulosus, gills were not systematically examined for pathological changes. However, the presence of spores of $H$. cynoscioni was verified in random gill squashes of heart-infected spotted seatrout. Therefore, we can conclude that $H$. cynoscioni, $H$. pagri and $H$. lateolabracis show a similar site specificity and 'behaviour' in their respective hosts. In this regard it would be most interesting to verify whether or not plasmodial stages of the fourth species of the cluster, $H$. tunisiensis, are formed exclusively on gill arches as documented by Bahri et al. (2010) or they occur also in the bulbus arteriosus of their hosts.

As a final note, the granulomatous lesions in the myocardium of spotted seatrout probably caused by eggs of the blood fluke Cardicola laruei as well as the high rate of their occurrence in $H$. cynoscioni-positive seatrout deserve further study. In this regard, we currently evaluate the possibility of synergic effect of lesions in two heart segments as putative impairment of heart function and health of the spotted seatrout.

Acknowledgements. Authors wish to thank the Inshore Fisheries Section of the Marine Research Resources Institute at the South Carolina Department of Natural Resources in Charleston for providing the fish as well as the Department of Biology at the College of Charleston for financial support. The J. William Fulbright Foreign Scholarship Board is acknowledged for selecting Iva Dyková for Fulbright grant supporting this research. Financial support was provided also by the Institute of Parasitology, Biology Centre of the Academy of Sciences of the Czech Republic (research projects Z60220518 and LC522). 
Azevedo C., Matos E. 1995: Henneguya adherens n. sp. (Myxozoa, Myxosporea), parasite of the Amazonian fish, Acestrorhynchus falcatus. J. Eukaryot. Microbiol. 42: 515-518.

Bahri S., Marton S., Marques A., Eszterbauer E. 2010: Henneguya tunisiensis $\mathrm{n}$. sp. (Myxosporea: Bivalvulida), a new gill parasite of Symphodus tinca (L.) (Teleostei: Labridae) off Tunisia. Syst. Parasitol. 76: 93-101.

Barta J.R., Martin D.S., Liberator P.A., DashKevicz M., Anderson J.W., Feighner S.D., Albrecht A., Perkins-Barrow A., Jenkins M.C., Danforth H.D., Ruff M.D., ProfousJuchelka H. 1997: Phylogenetic relationships among eight Eimeria species infecting domestic fowl inferred using complete small subunit ribosomal DNA sequences. J. Parasitol. 83: 268-271.

Blaylock R.B., Overstreet R.M. 2003: Diseases and parasites of the spotted seatrout. In: S.A. Bortone (Ed.), Biology of the Spotted Seatrout. CRC Press, NewYork, pp. 197-225.

Bortone S.A. (Ed.) 2003: Biology of the Spotted Seatrout. CRC Press, New York, 312 pp.

Bortone S.A., Wilzbach M.A., Beedee C.D. 1997: Indexed bibliography to the biology and life history of the spotted seatrout (Cynoscion nebulosus). Florida Center for Environmental Studies, Technical Series 1: i-iii, 1-74.

Castresana J. 2000: Selection of conserved blocks from multiple alignments for their use in phylogenetic analysis. Mol. Biol. Evol. 17: 540-552.

Dyková I., de Buron I., Fiala I., Roumillat W.A. 2009: Kudoa inornata sp. n. (Myxosporea: Multivalvulida) from the skeletal muscles of Cynoscion nebulosus (Teleostei: Sciaenidae). Folia Parasitol. 56: 91-98.

Froese R., Pauly D. (Eds.) 2010: FishBase. World Wide Web electronic publication, www.fishbase.org 10/2010.

Galtier N., Gouy M., Gautier C. 1996: SEAVIEW and PHYLO_WIN: two graphic tools for sequence alignment and molecular phylogeny. Comput. Appl. Biosci. 12: 543-548.

Hendon J.R., Warren J.R., Franks J.S., Buchanan M.V. 2002: Movements of spotted seatrout (Cynoscion nebulosus) in Mississippi coastal waters based on tag-recapture. Gulf Mex. Sci. 20: 91-97.

Icardo J.M., Colvée E., Cerra M.C., Tota B. 2000: The bulbus arteriosus of stenothermal and temperate teleosts: a morphological approach. J. Fish Biol. 57 (Suppl. A): 121-135.

Katoh K., Kuma K., Toh H., Miyata T. 2005: MAFFT version 5: improvement in accuracy of multiple sequence alignment. Nucl. Acids Res. 33: 511-518.

Lom J., Arthur J.R. 1988: A guideline for the preparation of species description in Myxosporea. J. Fish Dis. 12: 151-156.

McVay M.J., Bakenhaster M.D., Bullard S.A. 2011: Cardicola laruei Short, 1953 (Digenea: Aporocotylidae) from heart of seatrout, Cynoscion spp., (Perciformes: Sciaenidae) in the Gulf of Mexico and Atlantic Ocean: taxonomic redescription, first observations of egg and miracidium and comments on geographic distribution and host specificity. Comp. Parasitol. 78: 291-305.

Meyers T.R., Sawyer T.K., MacLean S.A. 1977: Henneguya sp. (Cnidospora: Myxosporida) parasitic in the heart of the bluefish, Pomatomus saltatrix. J. Parasitol. 63: 890-896.
Moravec F., De Buron I., Roumillat W.A. 2006: Two new species of Philometra (Nematoda: Philometridae) parasitic in the perciform fish Cynoscion nebulosus (Sciaenidae) in the estuaries of South Carolina, USA. Folia Parasitol. 53: 63-70.

Moser M., Love M.S. 1975: Henneguya sebasta sp. n. (Protozoa, Myxosporida) from California rockfish, Sebastes spp. J. Parasitol. 61: 481-483.

Perez G.R., Roumillat W.A., Levesque E.M., Connors V.A., DE BuRon I. 2008: Synchronization of occurrence of the ovarian philometrid, Philometra carolinensis, with the spawning season of its fish host, the spotted seatrout, Cynoscion nebulosus. Parasitol. Res. 104: 1079-1085.

Rajendran K.V., Vijayan K.K., Alavandi S.V. 1998: Cardiac myxosporiosis of pearl-spot, Etroplus suratensis (Bloch), due to Myxobolus etropli sp. nov. J. Fish Dis. 21: 169-176.

RIEKERK G.H. 1992: Ecology and microdistribution of selected metazoan parasites of the spotted seatrout, Cynoscion nebulosus (Pisces: Sciaenidae) in the Charleston Harbor estuary. M.S. thesis, University of Charleston, SC, $68 \mathrm{pp}$.

Robins C.R. (Ed.) 1991: Common and Scientific Names of Fishes from the United States and Canada. 5th Ed. Special Publication No. 20. American Fisheries Society, Bethesda, Maryland, 183 pp.

Roumillat W.A., Brouwer M.C. 2004: Reproductive dynamics of female spotted seatrout (Cynoscion nebulosus) in South Carolina. Fish. Bull. 102: 473-487.

Smith N.G., Jones C.M., Van Montfrans J. 2008: Spatial and temporal variability of juvenile spotted seatrout Cynoscion nebulosus growth in Chesapeake Bay. J. Fish Biol. 73: 597-607.

StAматакіS A. 2006: RAxML-VI-HPC: Maximum likelihoodbased phylogenetic analyses with thousands of taxa and mixed models. Bioinformatics 22: 2688-2690.

Swofford D.L. 2001: PAUP*. Phylogenetic Analysis Using Parsimony (*and Other Methods). Version 4. Sinauer Associates, Sunderland, Massachusetts.

Vanderkooy S.J., Muller R.G. 2003: Management of spotted seatrout and fishery participants in the U.S. In: S.A. Bortone (Ed.), Biology of the Spotted Seatrout. CRC Press, NewYork, pp. 227-245.

Ward R., Bowers K., Hensley R., Mobley B., Belouski E. 2008: Genetic variability in spotted seatrout (Cynoscion nebulosus) determined with microsatellite DNA markers. Fish. Bull. 105: 197-206.

Work T.M., Takata G., Whipps C.M., Kent M.L. 2008: A new species of Henneguya (Myxozoa) in the big-eyed scad (Selar crumenophthalmus) from Hawaii. J. Parasitol. 94: 524-529.

Yokoyama H., Iтон N., TANAKa S. 2005: Henneguya pagri $\mathrm{n}$. sp. (Myxozoa: Myxosporea) causing cardiac henneguyosis in red sea bream, Pagrus major (Temminck \& Schlegel). J. Fish Dis. 28: 479-487.

Yokoyama H., Kawakami H., Yasuda H., Tanaka S. 2003: Henneguya lateolabracis sp. n. (Myxozoa: Myxosporea), the causative agent of cardiac henneguyosis in Chinese sea bass Lateolabrax sp. Fish. Sci. 69: 1116-1120. 